23. ${ }^{*} 1881.0 \mathrm{~m}$ muskeltonen vid intermittent elektrisk retning samt om några i sammanhang därmed stående elektrisk-akustiska företeelser. Öfrers. af K. Vet.-Akad. Förh. 1881, S. 37-59. Deutsch: Ueber den Muskelton bei electrischer Reizung sowie über einige in Zusammenhang damit stehende electrisch-akustische Erscheinungen. Arch. f. Anat. u. Physiol., physiol. Abth,, 1881, S. 363-381. Abb. XIII.

24. 1883. Naggra betraktelser öfver den animaliska dragningskraften och dess användning. (Einige Betrachtungen über die thierische Zugkraft und deren Anwendung.) Landtbruksakademiens handlingar och tidskrift, 1883, 10 Seiten.

25. ${ }^{*} 1885$. Bidrag till kännedomen om hjärtförmakets förhållande vid direkt retning med enstaka induktionsslag. Akad. inbjudningsskrift. Nordiskt Medicinskt Arkiv, 17, Nr. 2, S. 1-16. Deutsch: Ueber die Einwirkung von einzelnen Inductionsschlägen auf den Vorbof des Froschherzens. Mitth. vom physiologischen Laboratorium des Carolinischen Instituts. Heft 4, S. 1-19. 1886. Abh. XIV.

26. *1896. Anders Retzius. Minnesord vid Svenska Läkaresällskapets fest till firande af 100-års-dagen af hans födelse. Hygiea, 58, S. 437 bis 459. Abh. XVII.

\title{
Sonstige Arbeiten aus dem Laboratorium Lovén's.
}

1877. C. H. Hildebrand, Bidrag till kännedomen om hjärtats förhållande vid direkt retning med enstaka induktionsslag. (Zur Kenntniss des Verbaltens des Herzens bei directer Reizung mit einzelnen Inductionsschlägen.) Nordiskt Medicinskt Arkiv, 9, Nr. 15, S. 1-13; 3 Tafeln.

1880. J. G. Edgren, Bidrag till läran om temperaturförhållandena i periferiska organ. Experimental-fysiologisk afhandling. (Beiträge zur Lehre von den Temperaturverhältnissen in peripheren Organen. Experimental-physiologische Untersuchung.) Ebenda 12, Nr. 26, S. 1-45; 13, Nr. 1, S. 1-30; 4 Tafeln.

1881. R. Tigerstedt, En ny metod för mekanisk retning af nerver. Ebenda 13 , Nr. 12, S. $1-15$.

1882. - Die durch einen constanten Strom in den Nerven hervorgerufenen Veränderungen der Erregbarkeit, mittels mechanischer Reizung untersucht. Bih. till K. Svenska Vet.-Akad. handl. 6, Nr. 22, S. 1-48; 10 Tafeln

1882. - Ueber innere Polarisation in den Nerven. Ebenda 7, Nr. 6, S. 1 bis $18 ; 4$ Tafeln.

1882. - Zur Theorie der Oeffnungszuckung. Ebenda 7, Nr. 7, S. 1-38; 1 Tafel.

1883. - und A. Willhard, Die Muskelzuckung in ihrer Abhängigkeit von der Stärke electrischer Reizung. Ebenda 8, Nr. 8, S. 1-20; 3 Tafeln. 
1883. R. Tigerstedt und J. Bergqvist, Zur Kenntniss der Apperceptionsdauer zusammengesetzter Gesichtsvorstellungen. Zeitschr. f. Biol., 19, S. 5-44; 1 Tafel.

1884. - und J. Bergq vist, Zur Methodik der Apperceptions-Versuche. Ebenda 20 , S. $135-139$.

1884. - und A. Willhard, Zur Kenntniss der Einwirkung von Inductionsströmen auf den Nerven. Bih. till K. Srenska Vet.-Akad. handl. 8, Nr. 16, S. $1-45 ; 2$ Tafeln.

1884. - Ueber den kleinsten subjectiv merkbaren Unterschied zwischen Reactionszeiten, nach Versuchen von K. Bogren und A. Willhard. Ebenda 8 , Nr. 17 , S. $1-31$.

\section{Robert Tigerstedt}

